\title{
Infectivity to Phlebotomus perniciosus of dogs naturally parasitized with Leishmania infantum after different treatments
}

\author{
Guadalupe Miró $^{1 *}$, Rosa Gálvez², Cristeta Fraile ${ }^{1}$, Miguel A Descalzo ${ }^{3}$ and Ricardo Molina²
}

\begin{abstract}
Background: In Europe most dogs with clinical leishmaniosis are treated with leishmanicides, typically antimonials combined with allopurinol and good clinical recovery is observed in a high number of these dogs. Through xenodiagnosis, the capacity of a treated animal to infect the vector of the disease under treatment is assessed as a measure of the chemotherapeutic efficacy of the drug used. The objective of the present study was to evaluate through direct xenodiagnosis the infectivity to Phlebotomus perniciosus of dogs naturally parasitized with Leishmania infantum after treatment, and to follow the clinical and parasite course of disease. Thirty two dogs with clinical leishmaniosis were assigned to one of three treatment groups: meglumine antimoniate plus allopurinol (Group A), meglumine antimoniate (Group B) or allopurinol (Group C). During the study, the dogs were examined before treatment (Day 0) and bimonthly thereafter until Day 180 (six months post-treatment onset).

Results: The three groups were scored over time according to the effects of treatment on clinical signs and clinical-pathological variables. Significant differences in clinical scores were observed between Group A and the other two groups, indicating the combined treatment was the most effective. After treatment, bone marrow cultures were positive for the parasite in $30.8 \%$ of dogs in some of the check ups (3 or $25 \%$ in Group A, 1 or $11.1 \%$ in Group B, and 4 or $80 \%$ in Group C). Our xenodiagnosis experiments revealed that $15.4 \%$ of treated dogs were still able to infect sand flies at some point after treatment (2 dogs or 16.6\% in Group A, 2 or 22.2\% in Group B and none in Group C). Only $7.7 \%$ of the entire study population could infect sand flies as from the second month posttreatment onset.

Conclusion: The three treatment regimens tested significantly reduced the infectivity of dogs towards sand flies, thus diminishing the epidemiological risks of treated dogs both for human beings and other healthy dogs. Despite its low cure rate, the use of allopurinol after a course of leishmanicide treatment is proposed to keep dogs noninfectious during the disease transmission season (4-6 months in southern Europe).
\end{abstract}

\section{Background}

Leishmaniosis caused by the protozoan Leishmania infantum is a severe parasitic disease that is spread to humans and animals by blood-sucking phlebotomine sand flies. Leishmaniosis is endemic in the Mediterranean basin. In Spain, the proven vectors for L. infantum are Phlebotomus perniciosus and Phlebotomus ariasi [1-3], the former being the main vector. Dogs are the main domestic reservoir of the parasite and play a role

\footnotetext{
* Correspondence: gmiro@vet.ucm.es

'Departamento de Sanidad Animal, Facultad de Veterinaria, Universidad

Complutense, Madrid, Spain

Full list of author information is available at the end of the article
}

in human infection [4]. Notwithstanding, the epidemiological role of the cat is today a subject of intense research [5-10] and it has been confirmed through direct xenodiagnosis that cats presenting clinical signs of the disease are able to infect sand flies [11,12].

Canine leishmaniosis (CanL) is today one of the most important imported canine diseases in Central Europe [13]. Estimates of CanL seroprevalence reported for Spain range from $3.7 \%$ for the Orense province in the northwest corner of the country [14] to $34.6 \%$ for the province of Málaga on the south coast [15]. In the Madrid region, a significant increase in the seroprevalence of CanL (from $5.25 \%$ to $8.1 \%$ ) and the densities of

\section{Biomed Central}


both its vectors ( $P$. perniciosus and $P$. ariasi) have been detected with respect to surveys conducted 15 and 17 years ago, respectively $[16,17]$.

Clinical CanL shows a wide spectrum of clinical signs because of the many pathogenic mechanisms involved and the particular host immune response [18]. However, in areas where the disease is endemic a large number of infected dogs are asymptomatic (clinically healthy infected dogs) [19] but remain infective to sand flies $[20,21]$. An early diagnosis and effective treatment of sick dogs could help prevent the disease spreading to other dogs and/or humans.

In Europe, treatment generally consists of various dosage regimens of leishmanicides (mainly pentavalent antimonials or secondly, miltefosine) combined with allopurinol (a leishmanistatic drug) [22-25]. Allopurinol has proved highly effective at maintaining successfully treated dogs in long term clinical remission. However, these treatments are of questionable efficacy because most treated dogs are clinically cured but remain infective [20,26,27].

To determine the epidemiologic risks of CanL, the role of the dog as a natural reservoir for L. infantum and the capacity of the sand fly vector to transmit infected forms of Leishmania need to be addressed. To date, few studies have assessed the infection capacity of treated $L$. infantum-parasitized dogs through xenodiagnosis $[20,26,28,29]$. This is because the method is complex and colonies of phlebotomine vectors need to be kept in laboratory conditions throughout a complete life cycle of the insect $[30,31]$.

This study was designed to assess through xenodiagnosis the infection capacity of dogs naturally infected with $L$. infantum before and after receiving three different treatment regimes, and to examine the clinical and parasite course.

\section{Methods}

\section{Animals}

This survey was carried out at the Veterinary Teaching Hospital of the Universidad Complutense de Madrid (Madrid, Spain). The dogs selected were 32 dogs infected with $L$. infantum that consecutively attended the clinic. The owners of the dogs enrolled were previously informed about the study protocol.

Dogs were included in the study if they met all the following criteria:

- at least two clinical signs consistent with CanL: asthenia and/or loss of weight, skin lesions, lymphoadenomegaly and/or splenomegaly, epistaxis sporadic or persistent (unilateral or bilateral), ocular lesions, alterations in digestive function and/or joints.
- a positive indirect immunofluorescence antibody test (IFAT) for leishmaniosis-specific antibodies (cut-off 1:100).

- parasite observed in cultures of bone marrow aspirates grown in Novy-Nicolle-McNeal medium and/ or promastigotes detected by direct xenodiagnosis.

Dogs with CanL were excluded if they fulfilled one of the criteria:

- concomitant infectious or vector-borne disease.

- pregnant or lactating female.

- severe renal, hepatic or cardiac failure.

- prior treatment with leishmanicides or corticosteroids.

\section{Sample collection}

Dogs were examined four times throughout the study: before treatment (Day 0) and at 60,120, and 180 days post-treatment (dpt) onset. On Day 0, dogs underwent an electrocardiogram to rule out heart disease. At each time point, blood, urine and bone marrow samples were collected and animals were scored for 13 clinical signs assessed in a physical examination using a categorized scoring system from 0 to 2 (Table 1 ).

Table 1 Scoring system used for the different clinical variables assessed before and after beginning treatment

\begin{tabular}{|c|c|c|c|}
\hline CLINICAL SIGNS & 0 & 1 & 2 \\
\hline Weight & normal & reduced & cachexia \\
\hline Appetite & normal & reduced & anorexia \\
\hline Behavior & normal & apathy & postration \\
\hline Lymphoadenomegaly & absent & localized & generalized \\
\hline Epistaxis & absent & moderate & severe \\
\hline Cutaneous keratoseborrhea & absent & moderate & generalized \\
\hline Ulcers & absent & simple & multiple \\
\hline Onicogriphosis & absent & moderate & severe \\
\hline Ocular lesions & absent & moderate & severe \\
\hline Digestive disorders & absent & mild & severe \\
\hline Arthropathy & absent & simple & multiple \\
\hline Amyotrophy & absent & moderate & severe \\
\hline Polyuria/Polydipsia & absent & moderate & severe \\
\hline $\begin{array}{l}\text { CLINICAL-PATHOLOGICAL } \\
\text { ABNORMALITIES }\end{array}$ & 0 & 1 & 2 \\
\hline Proteins & normal & elevated & reduced \\
\hline $\mathrm{A} / \mathrm{G}$ ratio & normal & reduced & - \\
\hline Urea & normal & elevated & - \\
\hline Creatinine & normal & elevated & - \\
\hline $\mathrm{ALT}$ & normal & elevated & - \\
\hline Complete blood count & \multicolumn{3}{|c|}{$\begin{array}{c}0=\text { normal, } 1=\text { anemia, } \\
2=\text { leukocytosis, } 5=\text { anemia }+ \\
\text { leukopenia, } 7=\text { anemia }+ \\
\text { leukocytosis }\end{array}$} \\
\hline
\end{tabular}


The clinical-pathological variables monitored were blood and urine data (urea, creatinine, ALT and protein electrophoresis). Additionally, the dogs were scored for 6 clinical-pathological abnormalities (Table 1). The IFAT for anti-Leishmania-specific immunoglobulin G (IgG) antibodies was performed as described previously [32] using the cut-off 1:100. Serum samples were also tested for the presence of anti-Ehrlichia canis IgG antibodies [33].

For each dog, we conducted selective culture of bone narrow aspirates on Novy-McNeal-Nicolle medium (NNN) and prepared three Giemsa-bone marrow smears to detect the presence of L. infantum amastigotes.

\section{Treatment protocol}

Dogs were assigned to one of the three treatment groups:

Group A: Meglumine antimoniate and allopurinol

- $35 \mathrm{mg} / \mathrm{kg}$ of meglumine antimoniate given subcutaneously twice daily for 28 days.

- $10 \mathrm{mg} / \mathrm{kg}$ of allopurinol given orally twice daily for six months.

Group B: Meglumine antimoniate

- $35 \mathrm{mg} / \mathrm{kg}$ of meglumine antimoniate given subcutaneously twice daily for 28 days.

Group C: Allopurinol

- $10 \mathrm{mg} / \mathrm{kg}$ of allopurinol given orally twice daily for six months.

\section{Xenodiagnosis}

The infectivity of dogs was assessed through direct xenodiagnosis. The local colony of $P$. perniciosus used in this study had been laboratory-reared at the Instituto de Salud Carlos III, Madrid [30]. The colony was kept in a chamber under controlled conditions of temperature $\left(27-28^{\circ} \mathrm{C}\right)$, relative humidity $(95-100 \%)$ and light cycle (17 hours light/7 hours dark).

Dogs were sedated by the intravenous injection of 0.5 $\mathrm{mg} / \mathrm{kg}$ of medetomidine and their heads introduced into individual cube-shaped nets $(50 \mathrm{~cm}$ wide $\times 50 \mathrm{~cm}$ high $\times 50 \mathrm{~cm}$ deep). Before treatment (Day 0) and 60, 120, and $180 \mathrm{dpt}$ onset, dogs were exposed for one hour to 100 unfed, 7-day-old female sand flies released inside the nets. After one hour of exposure, the sand flies were carefully collected using a mouth aspirator. Fed flies collected from each dog were separated into individual nets $(15 \times 15 \times 15 \mathrm{~cm})$. Next the dogs were removed from their cages and intravenously administered $0.25 \mathrm{mg} / \mathrm{kg}$ of atipamezole.
Fed sand flies were kept inside the chambers for 5-7 days. Engorged females were dissected and the sand fly midgut was examined under a light microscope to detect $L$. infantum promastigotes.

\section{Outcome variables}

The leismanicidal efficacy of treatment was assessed by examining bone marrow cultures over time. The infection capacity of the dogs was determined through xenodiagnosis at the different time points. The clinical course of the dogs was examined in each of the treatment groups by determining two indicators: percentage reduction in clinical score and percentage reduction in clinical-pathological abnormality score. Both of these indicators were calculated as: score Day 0 - score dpt/score Day 0).

\section{Statistical analysis}

Quantitative data for the clinical signs and clinical-pathological abnormalities monitored are provided as medians and their corresponding interquartile ranges. Categorical variables are given as percentages. Baseline variables were compared among the groups using the Chi-squared test, or Fisher's exact test for categorical variables. The KruskalWallis test was used to compare quantitative variables. To detect differences among groups and examine changes produced over time in the four outcome variables (leishmanicidal efficacy, infection capacity, percentage reduction in clinical signs and percentage reduction in clinical-pathological abnormalities), we constructed 4 longitudinal marginal models, one per outcome measure, using a generalized estimating equation (GEE) procedure. For leishmanicidal efficacy and infectivity to sand flies, marginal longitudinal models for binary data were used. Clinical sign and clinicalpathological abnormality percentage reductions were normalized by transforming these data into arc sen $\sqrt{p}$.

All analyses were performed using Stata v. 10.1 software (StataCorp LP, College Station, Texas, USA).

\section{Results}

Table 2 shows the baseline characteristics of the dogs in the three treatment groups revealing no significant differences among them $(p>0.1)$. All dogs showed clinical-pathological abnormalities associated with the disease. Of the 32 dogs initially recruited, 6 were withdrawn from the study ( 2 from Group B and 4 from Group C) for several reasons: clinical failure, pregnancy, diabetes, intestinal obstruction, surgery or death. This left a final study population of 26 dogs; 9 females and 17 males aged from 9 months to 9 years. Of these dogs, 16 were pure breed and 10 were mongrels.

\section{Leishmanicidal efficacy}

The results of the bone marrow cultures shown in Table 3 indicate a drop in the number of dogs positive for the 
Table 2 Baseline characteristics of the dogs included in the three different treatment groups

\begin{tabular}{lccc}
\hline & Group A & Group B & Group C \\
\hline AGE (years), median (p25-p75) & 12 & 11 & 9 \\
\hline PROT (g/dl), median (p25-p75) & $4(3-5)$ & $3(2-8)$ & $5(4-7)$ \\
\hline A/G (g/dl), median (p25-p75) & $8(7.6-10.1)$ & $7.2(6.8-9.8)$ & $8.5(7.4-8.8)$ \\
\hline UREA (mg/dl), median (p25-p75) & $0.44(0.38-0.49)$ & $0.46(0.36-0.57)$ & $0.43(0.42-0.66)$ \\
\hline CREAT (mg/dl), median (p25-p75) & $36(29-45)$ & $34(26-48)$ & $36(30-46)$ \\
\hline ALT (U/l), median (p25-p75) & $0.78(0.72-0.87)$ & $0.69(0.59-0.9)$ & $0.86(0.66-0.98)$ \\
\hline CLIN SCORE, median (p25-p75) & $67(45-100)$ & $57(46-146)$ & $89(54-98)$ \\
\hline ANALYTICAL SCORE, median (p25-p75) & $6(4-7)$ & $6(5-9)$ & $6(5-6)$ \\
\hline IFAT, median (p25-p75) & $5(3-10)$ & $3(3-4)$ & $3(2-4)$ \\
\hline CBC n, (\%) & $800(400-1600)$ & $800(800-1600)$ & $(200-400)$ \\
\hline
\end{tabular}

"Percentage of dogs showing abnormal CBC (anemia, leukocytosis or leukopenia).

CBC: complete blood count; ALT: Alanine trnsaminase; A/G: Albumin/Globulin ratio.

parasite produced in response to treatment in all three groups. In Group A, the 8 dogs testing positive (67\%) on Day 0 had dropped to 3 dogs (25\%) at $180 \mathrm{dpt}$ onset. In Group B, 9 dogs (100\%) initially testing positive, dropping to 1 dog (11\%) after 180 days of treatment and in Group $\mathrm{C}$, the corresponding numbers were $4(80 \%)$ and $1(20 \%)$. Our marginal longitudinal models revealed the significant $(p<0.001)$ and similar $(p>0.1)$ nature of these reductions from Day 60 across all three groups.

\section{Infectivity to sand flies}

Our xenodiagnosis experiments also revealed a considerable drop in the infectivity of the differently treated dogs in all 3 groups (Table 3). Thus, in Group A, numbers of infectious dogs over the study period fell from 8 (67\%) to no dogs. In Group B, numbers dropped from 6 (67\%) to $1(11 \%)$, and in Group C, from $3(60 \%)$ to zero. Marginal models once again indicated that these reductions were both similar $(\mathrm{p}>0.1)$ and significant $(\mathrm{p}<0.001)$ after 60 days post-treatment onset in all three groups.

\section{Clinical efficacy}

Before the onset of treatment, the 26 dogs showed a median clinical score of 6 points. When the clinical course of disease was assessed in terms of the mean reduction in this score, significant differences were detected over time $(\mathrm{p}<0.05)$ with respect to Day 0. When these reductions were compared among the groups, Group A treatment emerged as significantly more effective $(\mathrm{p}<0.05)$ compared to the other two treatment regimens (Figure 1).

Improved clinical-pathological abnormalities expressed as mean percentage reductions in scores observed indicated no significant differences $(\mathrm{p}<0.05)$, improvements being observed only with respect to baseline (Day 0 ) scores. After treatment, significant differences were
Table 3 Bone-marrow culture and xenodiagnosis results recorded before and after starting treatment in each dog

\begin{tabular}{|c|c|c|c|c|c|c|c|c|}
\hline \multirow[t]{2}{*}{ Dog } & \multicolumn{4}{|c|}{ Bone narrow culture } & \multicolumn{4}{|c|}{ Xenodiagnosis } \\
\hline & D0 & D60 & D120 & D 180 & Do & D60 & D120 & D 180 \\
\hline A1 & + & + & + & + & + & - & + & - \\
\hline $\mathrm{A} 2$ & + & - & - & + & + & - & - & - \\
\hline A3 & - & - & - & - & + & - & - & - \\
\hline A4 & + & - & - & - & - & - & - & - \\
\hline A5 & + & - & - & - & - & - & - & - \\
\hline A6 & - & - & - & - & + & - & - & - \\
\hline A7 & + & - & - & - & + & - & - & - \\
\hline A8 & - & - & - & - & + & - & - & - \\
\hline A9 & + & - & - & - & - & - & - & - \\
\hline $\mathrm{A} 10$ & - & - & - & - & + & - & - & - \\
\hline A11 & + & - & - & - & + & + & - & - \\
\hline $\mathrm{A} 12$ & + & - & - & + & - & - & - & - \\
\hline B1 & + & - & - & - & + & - & - & - \\
\hline B2 & + & - & - & - & + & + & - & - \\
\hline B3 & + & - & - & - & + & - & - & - \\
\hline B4 & + & - & - & + & - & - & - & + \\
\hline B5 & + & - & - & - & + & - & - & - \\
\hline B6 & + & - & - & - & - & - & - & - \\
\hline B9 & + & - & - & - & - & - & - & - \\
\hline B10 & + & - & - & - & + & - & - & - \\
\hline B11 & + & - & - & - & + & - & - & - \\
\hline $\mathrm{C} 1$ & - & - & - & - & + & - & - & - \\
\hline $\mathrm{C} 3$ & + & + & + & + & + & - & - & - \\
\hline C5 & + & + & - & - & + & - & - & - \\
\hline$C 7$ & + & - & + & - & - & - & - & - \\
\hline C9 & + & - & + & - & - & - & - & - \\
\hline
\end{tabular}

+ indicates positive culture result or infectious dog.

D0, D60, D120 and D180 indicate the time points before treatment and after 60,120 or 180 days of treatment respectively. 


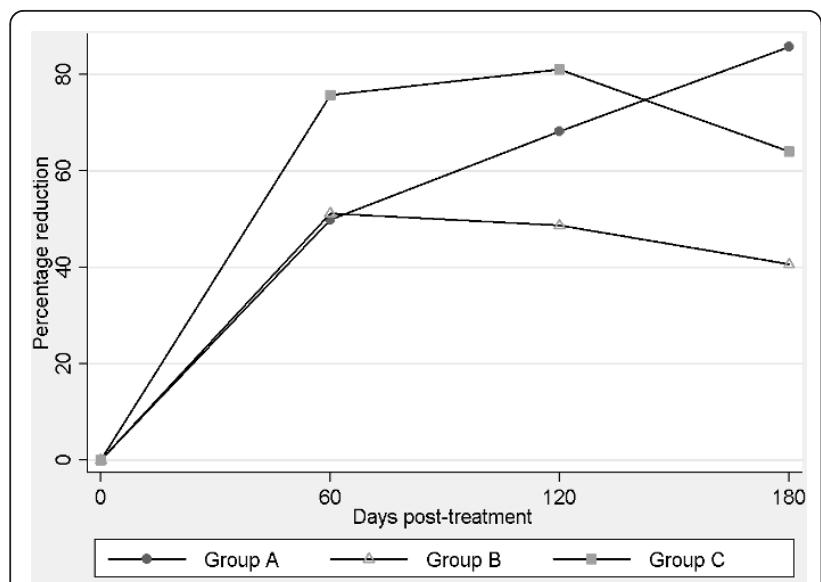

Figure 1 Percentage reductions in clinical signs produced in response to treatment.

detected among the three groups such that the Group A treatment emerged as more effective $(\mathrm{p}<0.05)$ than the remaining treatments (Figure 2).

\section{Discussion}

To date, the use of xenodiagnosis to assess the efficacy of treatment, measured as the infection capacity of treated dogs naturally infected with $L$. infantum, has only been reported in four studies including 4, 2, 36 and 10 dogs respectively $[20,26,28,29]$. The present survey along with the study by Ribero et al. (2008) [28] was conducted on a sufficiently large sample size for valid conclusions to be drawn.

As may be observed in Figures 1 and 2, the most effective of our treatment regimens in terms of clinical improvement was the combined use of antimonials and allopurinol (Group A). Notwithstanding, we and other authors have noted that in some measure all treatments

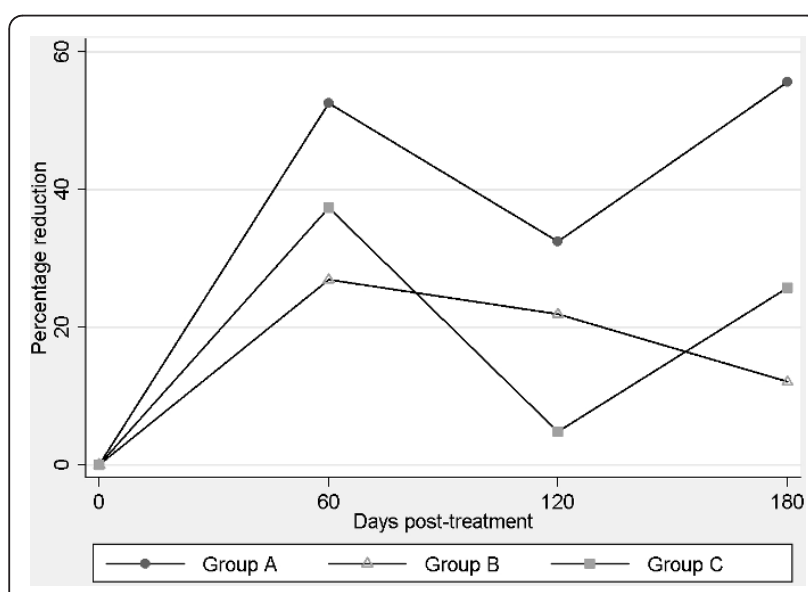

Figure 2 Percentage reductions in clinicopathological abnormalities produced in response to treatment. are able to improve the clinical condition of dogs $[20,26,28,29]$.

By examining the capacity of the dogs to infect sand flies, we observed a considerable reduction in the infectivity of the dogs in response to the three treatments tested. Only $7.7 \%$ of the entire study population was able to infect sand flies after the second month of treatment. This finding suggests that similarly treated dogs will not play a major role in promoting or maintaining new foci of disease spread.

The liposome formulation of meglumine antimoniate has been described to significantly diminish the capacity of dogs to infect Lutzomyia longipalpis five months after the end of treatment [28]. In prior work, we observed a lack of infectivity towards sand flies of 6 dogs treated with meglumine antimoniate and allopurinol for at least 4 months post-treatment onset [20]. In early studies, treatment with meglumine antimoniate was found to reduce the percentage of sand flies becoming infected after feeding on treated dogs [26,29].

The bone marrow culture results indicate that regardless of a favorable clinical outcome of treatment, $30.8 \%$ of the dogs still showed the presence of the parasite in some of the check ups. These animals can be described as not parasitologically cured, or carriers of the parasite.

In the survey conducted in Brazil, bone marrow parasite burden was significantly reduced 4 days after the end of treatment with meglumine antimoniate [28]. In addition, it was observed that five of six dogs treated with meglumine antimoniate plus allopurinol still harbored parasites in the spleen 10 months after treatment [20].

It should be highlighted that in the treatment Group $\mathrm{C}$ of the present study, $80 \%$ of the dogs remained infected at the end of the study. This would appear to point to the ineffective nature of treatments based solely on allopurinol since, despite showing clinical improvement, these still infected animals could experience disease recrudescence. However, xenodiagnosis of the dogs in Group $C$ indicated no evidence of the spread of the parasite to the phlebotomine sand flies. This finding has significant epidemiological implications in that although allopurinol may not be an effective shock treatment, it could perhaps be used in longer treatment maintenance courses (6-12 months). Notwithstanding, this should be done under supervision given the known long-term adverse effects of this agent (nephrolithiasis due to xanthine) [34,35].

The bone marrow culture and xenodiagnostic findings indicate that by Day 180 after the onset of treatment (A, B or C), $81 \%$ of the dogs had been "cured" or the parasite had been eliminated, although in some dogs (11.1 to $25 \%$ ) it persisted for a variable length of time. 
In conclusion, our results highlight the need to treat sick dogs since these represent a serious epidemiological risk. Despite not being a simple method, the xenodiagnostic approach used here emerged as a useful tool to assess the infection capacity of dogs treated with new drugs and/or new treatment regimens. A reduction in infectivity to sand flies in response to treatment is a key factor to consider in control programs designed to eradicate active foci of canine leishmaniosis. In endemic areas there is a plenty of evidence indicating the effectiveness of repellents against sand flies in reducing the spread of Leishmania infection.

\section{Acknowledgements}

The authors are indebted to the owners of all the dogs participating in this study. Publication of the CVBD6 thematic series was sponsored by Bayer Animal Health $\mathrm{GmbH}$.

\section{Author details}

${ }^{1}$ Departamento de Sanidad Animal, Facultad de Veterinaria, Universidad Complutense, Madrid, Spain. ${ }^{2}$ Servicio de Parasitología, Centro Nacional de Microbiología, Instituto de Salud Carlos III, Majadahonda, Madrid, Spain. ${ }^{3}$ Unidad de Investigación, Fundación Española de Reumatología, Madrid, Spain.

\section{Authors' contributions}

GM and RM designed, carried out the survey, drafted the first version of the manuscript and finalized the manuscript. RG helped with the xenodiagnosis experiments and finalized the manuscript. CF helped with the study design and carried out clinical experiments. MAD performed the statistical analysis of the data. All authors reviewed the manuscript.

\section{Competing interests}

The authors declare that they have no competing interests.

Received: 18 January 2011 Accepted: 13 April 2011

Published: 13 April 2011

\section{References}

1. Lucientes Curdi J, Acedo Sánchez C, Castillo Hernández JA, Estrada Peña A: Sobre la infección natural por Leishmania en Phlebotomus perniciosus Newstead, 1911 y Phlebotomus ariasi Tonnoir, 1921, en el foco de leishmaniosis de Zaragoza. Rev lber Parasitol 1988, 48:7-8.

2. Martín-Sánchez J, Guilvard E, Acedo-Sánchez C, Wolf-Echeverri M, SanchísMarín MC, Morillas-Márquez F: Phlebotomus perniciosus Newstead, 1911, infection by various zymodemes of the Leishmania infantum complex in the Granada province (southern Spain). Int J Parasitol 1994, 24:405-408.

3. Rioux JA, Guilvard E, Gállego J, Moreno G, Pratlong F, Portús M, Rispail P, Gállego M, Bastien P: Phlebotomus ariasi Tonnoir, 1921 et Phlebotomus perniciosus Newstead, 1911 vecteurs du complexe Leishmania infantum dans un même foyer: Infestations par deux zymodèmes syntopiques. A propos d'une enquête en Catalogne (Espagne). In Leishmania Taxonomie et Phylogenèse Applications Éco-Épidemiologiques Edited by: IMEEE. Montpellier 1986, 439-444.

4. Alvar J, Cañavate C, Molina R, Moreno J, Nieto J: Canine leishmaniasis. Adv Parasitol 2004, 57:1-88.

5. Ayllon T, Tesouro MA, Amusátegui I, Villaescusa A, Rodríguez-Franco F, Sainz A: Serologic and molecular evaluation of Leishmania infantum in cats from Central Spain. Ann N Y Acad Sci 2008, 1149:361-364.

6. Maia C, Nunes M, Campino L: Importance of cats in zoonotic leishmaniasis in Portugal. Vector Borne Zoonotic Dis 2008, 8:555-559.

7. Maia C, Nunes M, Cristovao J, Campino L: Experimental canine leishmaniasis: Clinical, parasitological and serological follow-up. Acta Trop 2010, 116:193-199.

8. Martín-Sánchez J, Acedo C, Muñoz-Pérez M, Pesson B, Marchal O, MorillasMárquez F: Infection by Leishmania infantum in cats: epidemiological study in Spain. Vet Parasitol 2007, 145:267-273.
9. Solano-Gallego L, Rodríguez-Cortés A, Iniesta L, Quintana J, Pastor J, Espada Y, Portus M, Alberola J: Cross-sectional serosurvey of feline leishmaniasis in ecoregions around the Northwestern Mediterranean. Am J Trop Med Hyg 2007, 76:676-680.

10. Tabar MD, Altet L, Francino O, Sánchez A, Ferrer L, Roura X: Vector-borne infections in cats: molecular study in Barcelona area (Spain). Vet Parasitol 2008, 151:332-336

11. Maroli M, Pennisi MG, Di Muccio T, Khoury C, Gradoni L, Gramiccia M: Infection of sandflies by a cat naturally infected with Leishmania infantum. Vet Parasitol 2007, 145:357-360.

12. da Silva SM, Rabelo PF, Gontijo Nde F, Ribeiro RR, Melo MN, Ribeiro VM, Michalick MS: First report of infection of Lutzomyia longipalpis by Leishmania (Leishmania) infantum from a naturally infected cat of Brazil. Vet Parasitol 2010, 174:150-154.

13. Naucke TJ, Menn B, Massberg D, Lorentz S: Sandflies and leishmaniasis in Germany. Parasitol Res 2008, 103(Suppl 1):S65-68.

14. Amusátegui I, Sainz A, Aguirre E, Tesouro MA: Seroprevalence of Leishmania infantum in northwestern Spain, an area traditionally considered free of leishmaniasis. Ann N Y Acad Sci 2004, 1026:154-157.

15. Morillas F, Sánchez Rabasco F, Ocaña J, Martín-Sánchez J, Ocana-Wihelmi J, Acedo C, Sanchís-Marín MC: Leishmaniosis in the focus of the Axarquia region, Malaga province, southern Spain: a survey of the human, dog, and vector. Parasitol Res 1996, 82:569-570.

16. Gálvez R, Descalzo MA, Miró G, Jiménez MI, Martín O, Dos SantosBrandao F, Guerrero I, Cubero E, Molina R: Seasonal trends and spatial relations between environmental/meteorological factors and leishmaniosis sand fly vector abundances in Central Spain. Acta Trop 2010, 115:95-102.

17. Gálvez R, Miró G, Descalzo MA, Nieto J, Dado D, Martín O, Cubero E, Molina R: Emerging trends in the seroprevalence of canine leishmaniosis in the Madrid region (central Spain). Vet Parasitol 2010, 169:327-334.

18. Solano-Gallego L, Koutinas A, Miró G, Cardoso L, Pennisi MG, Ferrer L, Bourdeau P, Oliva G, Baneth G: Directions for the diagnosis, clinical staging, treatment and prevention of canine leishmaniosis. Vet Parasitol 2009, 165:1-18.

19. Baneth G, Koutinas AF, Solano-Gallego L, Bourdeau P, Ferrer L: Canine leishmaniosis - new concepts and insights on an expanding zoonosis: part one. Trends Parasitol 2008, 24:324-330.

20. Alvar J, Molina R, San Andrés M, Tesouro M, Nieto J, Vitutia M, González F, San Andrés MD, Boggio J, Rodríguez F, y col.: Canine leishmaniasis: clinical, parasitological and entomological follow-up after chemotherapy. Ann Trop Med Parasitol 1994, 88:371-378.

21. Molina R, Amela C, Nieto J, San-Andrés M, González F, Castillo JA, Lucientes J, Alvar J: Infectivity of dogs naturally infected with Leishmania infantum to colonized Phlebotomus perniciosus. Trans $R$ Soc Trop Med Hyg 1994, 88:491-493.

22. Noli C, Auxilia ST: Treatment of canine Old World visceral leishmaniasis: a systematic review. Vet Dermatol 2005, 16:213-232.

23. Mateo M, Maynard L, Vischer C, Bianciardi P, Miró G: Comparative study on the short term efficacy and adverse effects of miltefosine and meglumine antimoniate in dogs with natural leishmaniosis. Parasitol Res 2009, 105:155-162

24. Manna L, Vitale F, Reale S, Picillo E, Neglia G, Vescio F, Gravino AE: Study of efficacy of miltefosine and allopurinol in dogs with leishmaniosis. Vet $J$ 2009, 182:441-445.

25. Miró G, Oliva G, Cruz I, Cañavate C, Mortarino M, Vischer C, Bianciardi P: Multicentric, controlled clinical study to evaluate effectiveness and safety of miltefosine and allopurinol for canine leishmaniosis. Vet Dermatol 2009, 20:397-404.

26. Gradoni L, Maroli M, Gramiccia M, Mancianti F: Leishmania infantum infection rates in Phlebotomus perniciosus fed on naturally infected dogs under antimonial treatment. Med Vet Entomol 1987, 1:339-342.

27. Travi BL, Ferro C, Cadena H, Montoya-Lerma J, Adler GH: Canine visceral leishmaniasis: dog infectivity to sand flies from non-endemic areas. Res Vet Sci 2002, 72:83-86

28. Ribeiro RR, Moura EP, Pimentel VM, Sampaio WM, Silva SM, Schettini DA, Alves CF, Melo FA, Tafuri WL, Demicheli C, et al: Reduced tissue parasitic load and infectivity to sand flies in dogs naturally infected by Leishmania (Leishmania) chagasi following treatment with a liposome formulation of meglumine antimoniate. Antimicrob Agents Chemother 2008, 52:2564-2572. 
29. Guarga JL, Moreno J, Lucientes J, Gracia MJ, Peribanez MA, Castillo JA: Evaluation of a specific immunochemotherapy for the treatment of canine visceral leishmaniasis. Vet Immunol Immunopathol 2002, 88:13-20.

30. Molina R: Laboratory adaptation of an autochtonous colony of

Phlebotomus perniciosus Newstead, 1911 (Diptera: Psychodidae). Reseach and Reviews in Parasitology 1991, 51:87-89.

31. Killick-Kendrick R, Killick-Kendrick M: The laboratory colonization of Phlebotomus ariasi (Diptera: Psychodidae). Ann Parasitol Hum Comp 1987, 62:354-356.

32. Mancianti F, Meciani N: Specific serodiagnosis of canine leishmaniasis by indirect immunofluorescence, indirect hemagglutination, and counterimmunoelectrophoresis. Am J Vet Res 1988, 49:1409-1411.

33. Sainz A, Delgado S, Amusategui I, Tesouro MA, Carmenes P.

Seroprevalence of canine ehrlichiosis in Castilla-Leon (north-west Spain). Preventive Veterinary Medicine 1996, 29:1-7.

34. Baneth G, Shaw SE: Chemotherapy of canine leishmaniosis. Vet Parasitol 2002, 106:315-324.

35. Ling GV, Ruby AL, Harrold DR, Johnson DL: Xanthine-containing urinary calculi in dogs given allopurinol. J Am Vet Med Assoc 1991, 198:1935-1940.

doi:10.1186/1756-3305-4-52

Cite this article as: Miró et al:: Infectivity to Phlebotomus perniciosus of dogs naturally parasitized with Leishmania infantum after different

treatments. Parasites \& Vectors 2011 4:52.

\section{Submit your next manuscript to BioMed Central} and take full advantage of:

- Convenient online submission

- Thorough peer review

- No space constraints or color figure charges

- Immediate publication on acceptance

- Inclusion in PubMed, CAS, Scopus and Google Scholar

- Research which is freely available for redistribution

Submit your manuscript at www.biomedcentral.com/submit 